\title{
LEGGETT-WILLIAMS FIXED POINT THEOREM TYPE FOR SUMS OF OPERATORS AND APPLICATION IN PDES
}

\author{
Svetlin Georgiev GeOrgiev And Karima Mebarki*
}

\begin{abstract}
In this paper we present an extension of the original version of Leggett-Williams fixed point theorem for a $k$-set contraction perturbed by an expansive operator. Our approach is applied to prove the existence of non trivial positive solutions for initial value problems (IVPs for short) covering a class two-dimensional nonlinear wave equations.
\end{abstract}

Mathematics subject classification (2020): 47H10, 47H08, 35L15.

Keywords and phrases: Fixed point index, cone, sum of operators, Green function, PDEs.

\section{REFERENCES}

[1] D. R. Anderson, R. I. Avery and J. Henderson, Functional Expansion-Compression Fixed Point Theorem of Leggett-Williams Type, Electron. J. Differential Equations, 2010, 63 (2010), 1-9.

[2] S. Benslimane, S. G. Geogiev and K. Mebarki, Expansion-Compression fixed point theorem of Leggett-Williams type for the sum of two operators and application in three-point BVPs, Accepted in Stud. Univ. Babeş-Bolyai Math.

[3] L. BEnZENATI AND K. MEBARKI, Multiple positive fixed points for the sum of expansive mappings and $k$-set contractions, Math. Meth. Appl. Sci. 42, 13 (1919), 4412-4426.

[4] L. Benzenati, S. G. Georgiev and K. Mebarki, Existence of positive solutions for some kinds of BVPs in Banach spaces, Accepted in Studia Universitatis Babeş-Bolyai Mathematica.

[5] S. Djebali And K. Mebar KI, Fixed point index theory for perturbation of expansive mappings by $k$-set contraction, Top. Meth. Nonli. Anal., 54, 2 (2019), 613-640, doi:10.12775/TMNA.2019.055.

[6] D. DufFY, Green's function with Applications, CRC Press, 2001.

[7] D. Guo, Y. I. Cho And J. Zhu, Partial Ordering Methods in Nonlinear Problems, Shangdon Science and Technology Publishing Press, Shangdon, 1985.

[8] S. G. GEORGIEV AND K. MEBARKI, Existence of positive solutions for a class ODEs, FDEs and PDEs via fixed point index theory for the sum of operators, Communications on Applied Nonlinear Analysis, 26, 4 (2019), 16-40.

[9] S. G. GEORGIEV AND K. MEBAR KI, On fixed point index theory for the sum of operators and applications in a class ODEs and PDEs, Accepted in Applied General Topology.

[10] K. G. Mavridis, Two Modifications of The Leggett-Williams Fixed Point Theorem and Their Applications, Electron. J. Differential Equations, 2010, 53 (2010), 1-11.

[11] R. W. Leggett AND L. R. Williams, Multiple positive fixed-points of nonlinear operators on orderd Banach spaces, Indiana University Mathematics Journal, 28 (1979), 673-688.

[12] A. Polyanin AND A. ManZhirov, Hoandbook of integral equations, CRC Press, 1998. 